support from: AstraZeneca, Celgene, Compugen, Novartis, Roche, UCB Pharma, Consultant for: AbbVie, Celgene, Galvani, Lilly, Novartis, Pfizer, UCB Pharma DOI: 10.1136/annrheumdis-2019-eular.4883

\section{OP0109 EFFICACY OF FILGOTINIB VS PLACEBO IN ACTIVE PSORIATIC ARTHRITIS: PATIENT-LEVEL DATA FROM EQUATOR, A RANDOMIZED, PHASE 2 STUDY}

Philip J Mease ${ }^{1}$, Dafna D Gladman², Filip van den Bosch ${ }^{3}$, Mykola Stanislavchuk ${ }^{4}$ Anna Rychlewska-Hanczewska ${ }^{5}$, Chantal Tasset ${ }^{6}$, Luc Meuleners ${ }^{6}$,

Robin Besuyen ${ }^{7}$, Jingjing Gao ${ }^{8}$, Mona Trivedi ${ }^{8}$, Laura C Coates ${ }^{9}$, Philip Helliwell ${ }^{10}$ ${ }^{1}$ Swedish Medical Center/Providence St Joseph Health and University of

Washington, Seattle, United States of America; ${ }^{2}$ University of Toronto and Krembil Research Institute, Toronto Western Hospital, Toronto, Canada; ${ }^{3}$ Ghent University Hospital, Ghent, Belgium; ${ }^{4}$ National Pirogov Memorial Medical University, Vinnytsya, Ukraine; ${ }^{5}$ Ai Centrum Medyczne, Poznan, Poland; ${ }^{6}$ Galapagos NV, Mechelen, Belgium; ${ }^{7}$ Galapagos BV, Leiden, Netherlands; ${ }^{8}$ Gilead Sciences, Inc., Foster City, United States of America; ${ }^{9}$ University of Oxford, Oxford, United Kingdom; ${ }^{10}$ Leeds Institute of Rheumatic and Musculoskeletal Medicine, Leeds, United Kingdom

Background: Filgotinib (FIL) is an oral, selective Janus kinase 1 inhibitor in development for the treatment of several inflammatory diseases. In the phase 2 EQUATOR trial (NCT03101670), FIL was efficacious vs placebo (PBO) in patients with active psoriatic arthritis (PsA), and was well tolerated [1]

Objectives: To evaluate the onset and maintenance of response to FIL vs PBO in EQUATOR by evaluating patient-level response over time.

Methods: EQUATOR was a 16-week, multicenter, double-blind study in which patients with active PSA were randomized 1:1 to FIL $200 \mathrm{mg}$ or PBO once daily [1]. Disease activity was assessed at screening, day 1 and weeks 1, 2, 4, 8, 12 and 16 , and the primary efficacy endpoint was the proportion of patients achieving $20 \%$ American College of Rheumatology (ACR20) response. The onset of response was assessed by calculating the median time to ACR20 response using the Kaplan-Meier method and compared between FIL and PBO using the log-rank test. Maintenance of response was assessed by analysing ACR20 response patterns over time in the FIL and PBO groups.

Results: Of 131 patients randomized (FIL: $n=65$; PBO: $n=66), 124$ (95\%) completed the study. Demographics and baseline disease characteristics were similar between groups. The onset of response to FIL was early, with a median (95\% confidence interval) time to first ACR20 response of 4.07 weeks $(2.29,4.14)$ in the FIL group compared with 12.29 weeks $(12$, not reached) in the $\mathrm{PBO}$ group $(\mathrm{p}<0.0001$; Figure 1). ACR20 responses were achieved at week 16 in $80.0 \%(52 / 65)$ and $33.3 \%(22 / 66)$ of patients in the FIL and PBO groups, respectively, using the nonresponder imputation method, and $86.7 \%(52 / 60)$ and $34.4 \%(22 / 64)$, respectively, using observed cases. The number of patients who presented with a stable ACR20 response (i.e. the response was maintained once initially achieved regardless of the time point at which the patient first became a responder) among those who were responders at week 16 (i.e. the primary endpoint) was higher in the FIL group than in the PBO group (80.8\% [42/52] vs 68.2\% [15/22]) (Figure 2). Similar trends were observed for other efficacy endpoints representing various manifestations of PsA.

Conclusion: In general, patients treated with FIL achieved an ACR20 response earlier than those on PBO and these responses appeared to be more stable. In
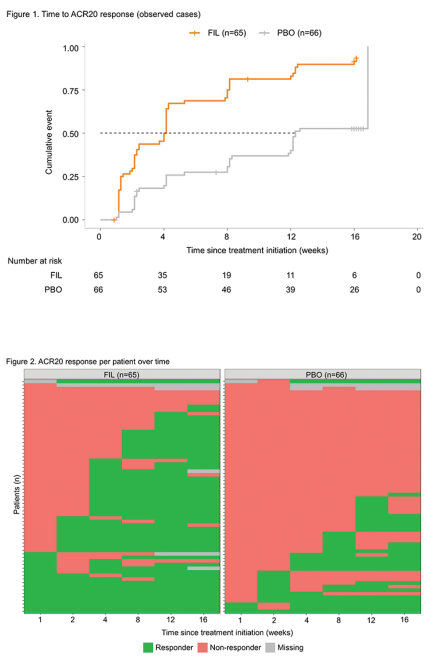

the PBO group, there were more occurrences of the response being lost over time and fewer cases of regaining a lost response.

\section{REFERENCE:}

[1] Mease P, et al. Lancet 2018;392:2367-77.

Acknowledgement: This study was funded by Galapagos NV (Mechelen, Belgium). Medical writing support was provided by Alice Wareham PhD, CMPP (Aspire Scientific Ltd, Bollington, UK) and funded by Galapagos NV.

Disclosure of Interests: Philip J Mease Grant/research support from: AbbVie, Amgen, BMS, Celgene, Janssen, Lilly, Novartis, Pfizer, SUN and UCB, Consultant for: AbbVie, Amgen, BMS, Galapagos, Gilead Sciences, Inc., Janssen, Lilly, Novartis, Pfizer, SUN and UCB, Speakers bureau: AbbVie, Amgen, BMS, Celgene, Genentech, Janssen, Lilly, Novartis, Pfizer and UCB, Dafna D Gladman Grant/research support from: AbbVie, Amgen, Celgene, Lilly, Novartis, Pfizer and UCB, Consultant for: AbbVie, Amgen, BMS, Celgene, Galapagos, Gilead, Janssen, Lilly, Novartis, Pfizer, and UCB, Filip van den Bosch Consultant for: AbbVie, BMS, Galapagos, Janssen, Lilly, Merck, Novartis, Pfizer and UCB, Speakers bureau: AbbVie, BMS, Janssen, Lilly, Merck, Novartis, Pfizer and UCB., Mykola Stanislavchuk Grant/research support from: AstraZeneca, Celltrion, Galapagos Genentech, GlaxoSmithKline, Human Genome, Lilly, Medlmmune, Pfizer, Roche and UCB, Anna Rychlewska-Hanczewska Grant/research support from: Galapagos and Gilead Sciences, Inc., Chantal Tasset Shareholder of: Warrants from Galapagos, Employee of: Galapagos, Luc Meuleners Shareholder of: Warrants from Galapagos, Employee of: Galapagos, Robin Besuyen Shareholder of: Warrants from Galapagos, Employee of: Galapagos, Jingjing Gao Shareholder of: AbbVie and Gilead Sciences, Inc., Employee of: Gilead Sciences, Inc., Mona Triv edi Shareholder of: Amgen and Gilead Sciences, Inc., Employee of: Gilead Sciences, Inc., Laura C Coates Grant/research support from: AbbVie, Celgene, Lilly, Novartis and Pfizer, Consultant for: AbbVie, Amgen, BMS, Celgene, Galapagos, Gilead Sciences Inc., Janssen, Lilly, Novartis, Pfizer, Prothena Corp and UCB, Philip Helliwell Grant/research support from: Paid to charity: from AbbVie, Jans sen and Novartis, Consultant for: Paid to charity: from AbbVie, Amgen, Pfizer, and UCB and Celgene. Paid to self: from Celgene and Galapagos

DOI: 10.1136/annrheumdis-2019-eular.6064

\section{OP0110 \\ IXEKIZUMAB IMPROVES SIGNS AND SYMPTOMS OF PSORIATIC ARTHRITIS IN PATIENTS WHO HAVE HAD INADEQUATE RESPONSE TO 1 OR 2 TUMOR NECROSIS FACTOR INHIBITORS}

L Bruce Kirkham ${ }^{1}$, Carlos Sesin ${ }^{2}$, Aubrey Trevelin Sprabery ${ }^{3}$, Chen-Yen Lin ${ }^{3}$ Amanda M. Gellett ${ }^{3}$, Anthony Turkiewicz ${ }^{4} .{ }^{1}$ Guy's Hospital, London, United Kingdom; ${ }^{2}$ Mount Sinai Medical Center, Miami, United States of America; ${ }^{3}$ Eli Lilly and Company, Indianapolis, United States of America; ${ }^{4}$ Rheumatology Associates, Birmingham, United States of America

Background: Psoriatic arthritis (PsA) is a progressive, chronic inflammatory dis ease often treated with tumor necrosis factor inhibitors (TNFi) when conventional treatments fail. Patients with inadequate response to TNFi represent a more difficult-to-treat population.

Objectives: To report the efficacy of ixekizumab (IXE), a monoclonal antibody that selectively targets interleukin-17A, in patients with inadequate response to 1 TNFi or 2 TNFi.

Methods: In a Phase 3 study (SPIRIT-P2; NCT02349295), patients who had an inadequate response or intolerance to 1 or $2 \mathrm{TNFi}$ were randomized to receive subcutaneous IXE $80 \mathrm{mg}$ every 2 weeks (IXEQ2W; $\mathrm{N}=123$ ) or every 4 weeks (IXEQ4W; $\mathrm{N}=122$ ), after a 160-mg starting dose, or placebo (PBO; $\mathrm{N}=118$ ) for up to 24 weeks. At Week 16, patients not meeting predefined criteria $(<20 \%$ improve ment in tender joint count [TJC] and swollen joint count [SJC]) received rescue therapy and were imputed as nonresponders at Weeks 20 and 24. At Week 24, PBO patients were rerandomized to IXEQ2W or IXEQ4W through Week 52 and excluded from the 52-week analysis. At Week 32 or any subsequent visit, patients were discontinued if they did not reach $\geq 20 \%$ improvement from baseline in both TJC and SJC. These ad-hoc data were derived from patients in the intent-to-treat population with prior inadequate response to TNFi; intolerant patients were excluded from the analysis. Efficacy was measured by percentage of patients who attained $\geq 50 \%$ improvement in American College of Rheumatology response criteria (ACR50), an improvement in Health Assessment QuestionnaireDisability Index (HAQ-DI) $\geq 0.35$, minimal disease activity (MDA), Disease Activity Score 28 - C-reactive protein (DAS28-CRP) EULAR Good Response criteria, and Disease Activity in Psoriatic Arthritis (DAPSA) $\leq 14$.

Results: At baseline, 1-TNFi inadequate responders were, on average, 52 years of age with a PsA diagnosis for 10 years; $40 \%$ were using MTX, and HAQ-DI was 1.2. 2-TNFi inadequate responders were 52 years of age with a PsA diagnosis for 11 years; $42 \%$ were using MTX, and HAQ-DI was 1.3. Regardless of inadequate response to 1 or $2 \mathrm{TNFi}$, at Week 24 significantly more patients receiving Q4W or 